\title{
Paisagens transformadas: a arqueologia de povos Jê no Paraná, sul do Brasil
}

Claudia Inês Parellada*

PARELLADA, C.I., Paisagens transformadas: a arqueologia de povos Jê no Paraná, sul do Brasil. R. Museu Arq. Etn., 27: 158-167, 2016

Resumo: No estudo foram analisados sítios Itararé-Taquara no Paraná, especialmente paleo-aldeias e abrigos-sob-rocha, em relação à estrutura e à transformação da paisagem, discutindo dados geoarqueológicos e cronológicos, de 4.000 a 600 anos atrás. A disposição espacial de aldeias, habitações e áreas sagradas em relação ao relevo, a mobilização de terra com a construção de aterros com formatos circulares a lineares, a escavação de estruturas semi-subterrâneas, com funções variadas, permitem refletir sobre aspectos simbólicos dos povos Jê pré-coloniais no Paraná, sul do Brasil. Além disso, o uso de monolitos para observação astronômica visava uma melhor compreensão dos ciclos da natureza que refletia numa agricultura mais produtiva. No alto Ribeira, houve uma concentração Jê, entre 1000 e 700 anos atrás, com paisagens ocupadas, na planície litorânea ou em relevo montanhoso, com grandes desníveis altimétricos, através de domínio dos diferentes tipos de solos e rochas. Alguns locais foram selecionados e transformados para marcar o controle e o domínio do território, e assim perpetuar uma memória mítica.

Palavras-chave: Arqueologia do Paraná; Ceramistas Itararé-Taquara; Arqueologia da paisagem; Arqueologia Jê; Arte rupestre

\section{Introdução: Jê no Paraná}

Чá mais de 4.000 anos atrás, com o

I clima tornando-se mais quente e úmido, as matas de araucária em expansão e os campos e estepes diminuindo (Bauermann \& Behling 2009) aparecem os primeiros ceramistas e agricultores, em território do atual Estado do Paraná, sendo relacionados a povos da família linguística Jê . Possivelmente já fossem as populações cujos vestígios nos planaltos do sul do Brasil são atribuídos aos Itararé-Taquara (Chmyz 1968a, b; Schmitz 1988; Araújo 2001; Beber 2004; Parellada 2005).

* Pesquisadora do Museu Paranaense. <cparellada34@gmail.com>
Os povos Jê teriam iniciado a migração de regiões centrais da América do Sul em direção ao sul, há mais de três mil anos, buscando paisagens tradicionais (Urban 1992). Com os dados atuais supõe-se ter acontecido troca genética, além de dinâmica cultural, entre os que migravam e os diferentes grupos caçadorescoletores que ocupavam o Paraná. Os primeiros grupos Jê, com cerâmica fina e lisa, distribuíram-se, inicialmente, nas proximidades do rio Paraná, entre os vales do Ivaí e Iguaçu, direcionando-se a áreas montanhosas dos Campos Gerais, Serra do Mar e ainda a planícies costeiras, e por uma outra entrada pelas terras altas no nordeste paranaense com posterior migração a outros espaços (verificar locais e datações nas tabelas 1 e 2 e na figura 1 ). 


\begin{tabular}{|c|c|c|c|c|}
\hline No & $\begin{array}{l}\text { Município do Paraná, sítio arqueológico, } \\
\text { perfil ou quadra, profundidade }\end{array}$ & No da amostra & $\begin{array}{l}\text { Data anos } \\
\text { (AP) }\end{array}$ & $\begin{array}{l}\text { Referências } \\
\text { bibliográficas }\end{array}$ \\
\hline 1 & Guaporema, José Vieira, nível intermediário & GSY 82 & $3435 \pm 175$ & $\begin{array}{l}\text { Laming \& Emperaire } \\
1959\end{array}$ \\
\hline 2 & $\begin{array}{l}\text { Jaguariaíva, Abrigo Jaguariaíva 1, quadra } 2 \text {, } \\
\text { nível 3B }\end{array}$ & LACUFF 150050 & $2858+35$ & Parellada 2015 \\
\hline 3 & UHE Salto Santiago, margem direita & & 2860 & Chmyz com 2002 \\
\hline 4 & UHE Salto Osório, margem esquerda & & 2445 & Chmyz com 2002 \\
\hline 5 & UHE Salto Osório, margem direita & & 2355 & Chmyz com 2002 \\
\hline 6 & $\begin{array}{l}\text { Ventania, Caverna Morro Azul 1, } \\
\text { quadra } 1 \text {, nível } 12 \mathrm{~cm}\end{array}$ & LACUFF 150057 & $1941 \pm 35$ & Parellada 2015 \\
\hline 7 & Sengés, Abrigo Janela 1 , quadra $3,15 \mathrm{~cm}$ & ANUA 19227 & $1790 \pm 210$ & Parellada 2005 \\
\hline 8 & Bituruna, PR UV 47, Linha Navegantes 2 & SI 5014 & $1635 \pm 100$ & Chmyz et al. 2009 \\
\hline 9 & União da Vitória, Abrigo Bruacas PR UV 17 & SI 2197 & $1475 \pm 65$ & Chmyz 1981 \\
\hline 10 & Bituruna, PR UV 48, Rio Jararaca & BETA 22647 & $1420 \pm 50$ & Chmyz et al. 2009 \\
\hline 11 & $\begin{array}{l}\text { São Mateus do Sul, PR SM 16, habitação } \\
\text { subterrânea }\end{array}$ & BETA256211 & $1150 \pm 40$ & Chmyz et al. 2009 \\
\hline 12 & Ortigueira, PR SA 34, Arroio Belo, hab sub & LACIVID TL & $1130 \pm 60$ & Chmyz et al. 2008 \\
\hline 13 & $\begin{array}{l}\text { Piraquara, } 1 \text { Eixo Bar Piraquara, quadra 2, } \\
\text { nível } 55 \mathrm{~cm}\end{array}$ & LACUFF 150048 & $1051 \pm 37$ & Parellada 2015 \\
\hline 14 & $\begin{array}{l}\text { São Mateus do Sul, PR SM 17, habitação } \\
\text { subterrânea B, nível inferior }\end{array}$ & BETA 256210 & $1030 \pm 50$ & Chmyz et al. 2009 \\
\hline 15 & $\begin{array}{l}\text { Mandirituba, PR CT 93, habitação } \\
\text { subterrânea, c } 1\end{array}$ & BETA 180903 & $940 \pm 70$ & Chmyz et al. 2003 \\
\hline 16 & $\begin{array}{l}\text { Foz do Jordão, Eixo Barrragem } 7 \text { Fundão, } \\
\text { quadra 7, nível } 60 \mathrm{~cm}\end{array}$ & LACUFF 150056 & $922 \pm 33$ & Parellada. 2015 \\
\hline 17 & $\begin{array}{l}\text { São Mateus do Sul, PR SM 17, habitação } \\
\text { subterrânea A, nível inferior }\end{array}$ & BETA 256209 & $920 \pm 40$ & Chmyz et al. 2009 \\
\hline 18 & $\begin{array}{l}\text { Dr. Ulysses, Fazenda Marrecas 4, } \\
\text { quadra 1A, nível } 27 \mathrm{~cm}\end{array}$ & ANUA 19223 & $890 \pm 180$ & Parellada. 2005 \\
\hline 19 & Ubiratã, PR UB 4, aterro, cremação & SI 2193 & $855 \pm 95$ & Chmyz, 1981 \\
\hline 20 & $\begin{array}{l}\text { Mandirituba, PR CT 93, habitação } \\
\text { subterrânea, c } 2\end{array}$ & BETA 180904 & $850 \pm 50$ & Chmyz et al., 2003 \\
\hline 21 & Campo Largo, PR CT 53, Palmeira 3 & BETA 22644 & $848 \pm 70$ & Chmyz 1995 \\
\hline 22 & Curiúva, PR SA 6, Camargo 2 & LACIVID-TL & $837 \pm 60$ & Chmyz et al. 2008 \\
\hline 23 & Bituruna, PR UV 12, hab sub, 60 a $80 \mathrm{~cm}$ & SI 892 & $810 \pm 90$ & Chmyz et al. 2003 \\
\hline 24 & União da Vitória, Abrigo PR UV 1 & SI 141 & $800 \pm 50$ & Chmyz 1968a \\
\hline 25 & Ubiratã, PR UB 4, Caraja I, hab sub. & SI 2194 & $735 \pm 95$ & Chmyz 1981 \\
\hline 26 & Curiúva, PR SA 8, Cangaia & LACIVID-TL & $735 \pm 50$ & Chmyz et al. 2008 \\
\hline 27 & $\begin{array}{l}\text { Dr. Ulysses, Walgimiro Matos 1, quadra } 3 \text {, } \\
\text { nível } 15 \mathrm{~cm}\end{array}$ & ANUA 19224 & $730 \pm 150$ & Parellada 2005 \\
\hline
\end{tabular}

Tabela 1: Datações radiocarbônicas ou por termoluminiscência (TL) de sítios Itararé-Taquara no Paraná, sul do Brasil (parte 1). 


\begin{tabular}{lllll}
\hline No & \multicolumn{1}{c}{$\begin{array}{c}\text { Município do Paraná, sítio arqueológico, } \\
\text { perfil ou quadra, profundidade }\end{array}$} & No da amostra & $\begin{array}{l}\text { Data anos } \\
\text { (AP) }\end{array}$ & $\begin{array}{c}\text { Referências } \\
\text { bibliográficas }\end{array}$ \\
\hline 28 & Arapoti, PR WB 1, Rio Laranjinha & LACIVID-TL & $706 \pm 47$ & Chmyz et al. 2008 \\
29 & $\begin{array}{l}\text { Mandirituba, PR CT 93, habitação } \\
\text { subterrânea, c 13 }\end{array}$ & BETA 180907 & $680 \pm 70$ & Chmyz et al. 2003 \\
30 & Bituruna, PR UV 11, aterro & SI 1010 & $680 \pm 70$ & Chmyz et al. 2003 \\
31 & $\begin{array}{l}\text { Mandirituba, PR CT 93, habitação } \\
\text { subterrânea, c 8 }\end{array}$ & BETA 180906 & $660 \pm 60$ & Chmyz et al. 2003 \\
32 & Arapoti, PR WB 5, Rio do Café 2 & LACIVID-TL & $654 \pm 43$ & Chmyz et al. 2008 \\
33 & Mandirituba, PR CT 91, habitação & LACIVID-TL & $650 \pm 45$ & Chmyz et al. 2003 \\
& subterrânea, c 1 & LACIVID-TL & $636 \pm 43$ & Chmyz et al. 2008 \\
34 & Arapoti, PR WB 3, Rio Café 1 & $623 \pm 120$ & Chmyz 1981 \\
35 & Bituruna, PR UV 12, Zampieron 1, hab sub & SI 1010 & $605 \pm 120$ & Chmyz 1981 \\
36 & Bituruna, PR UV 12, hab sub, 40 a 60 cm & SI 691 & $595 \pm 60$ & Chmyz 1981 \\
37 & Mangueirinha, PR MN 4, aterro & SI 6396 & $580 \pm 60$ & Chmyz et al. 2003 \\
38 & Mandirituba PR CT 93 habitação & BETA 180905 & & \\
& subterrânea, c 4 & & & \\
39 & Curiúva, PR RP 10, Rio Alecrim 1 & LACIVID-TL & $560 \pm 60$ & Chmyz et al. 2008 \\
40 & Arapoti, Abrigo PR WB 16, superior & LACIVID-TL & $504 \pm 40$ & Chmyz et al. 2008 \\
41 & Arapoti, PR SA 2, Bairro do Felisberto & LACIVID-TL & $504 \pm 40$ & Chmyz et al. 2008 \\
42 & São Mateus do Sul, PR SM 14, Erveiras & BETA 256208 & $490+40$ & Chmyz et al 2009 \\
43 & Ubiratã, PR UB 4, cremação, aterro & SI 2192 & $470 \pm 95$ & Chmyz 1981 \\
44 & Campo Largo, PR CT 53, Palmeira 3 & BETA 22646 & $458 \pm 50$ & Chmyz 1995 \\
45 & Bituruna, PR UV 12, cemitério, hab sub & SI 692 & $255 \pm 100$ & Chmyz et al. 2003 \\
46 & Porto Vitória, PR UV 38, Prainha & SI 5013 & $190+75$ & Chmyz et al. 2009 \\
\hline
\end{tabular}

Tabela 2: Datações radiocarbônicas ou por termoluminiscência (TL) de sítios Itararé-Taquara no Paraná, sul do Brasil (parte 2).

Entre os séculos XV a XIX parece ter acontecido a entrada de outros povos Jê, os Aratu, com sítios arqueológicos caracterizados no centro e norte do Paraná, nos municípios de Apucarana (Schmitz \& Rogge 2008), Prudentópolis e Cambé, entre outros. Possivelmente relacionados aos Kayapó do Sul, Ofaié ou Oti-Xavante, descritos em locais próximos, no início do século XX, em Nimuendaju (1981).

A ocupação Itararé-Taquara foi, preferencialmente, em planaltos cobertos por campos associados à floresta subtropical com pinheiros araucária, havendo assentamentos em vales de rios, no litoral e na serra atlântica, nos abrigos, cavernas e estruturas semi-subterrâneas, que possuíam grande diferenciação de usos, além de áreas de antigos sambaquis na costa litorânea e de acampamentos Umbu (Chmyz 1968a, b, 1995; Chmyz \& Sauner 1971; Schmitz 1988, 1991; Parellada 2007; Souza \& Merencio 2013).

São relacionados monólitos, alinhamentos de pedras e megalitos, discutidos em Langer e Santos (2002), no vale do médio Iguaçu, alguns possíveis observatórios astronômicos, e sepultamentos com pedras no médio Ribeira e Tibagi, descritos por Robrahn (1989) e Mota el al. (2005). Alguns sítios são multicomponenciais, geralmente com mais de uma ocupa- 


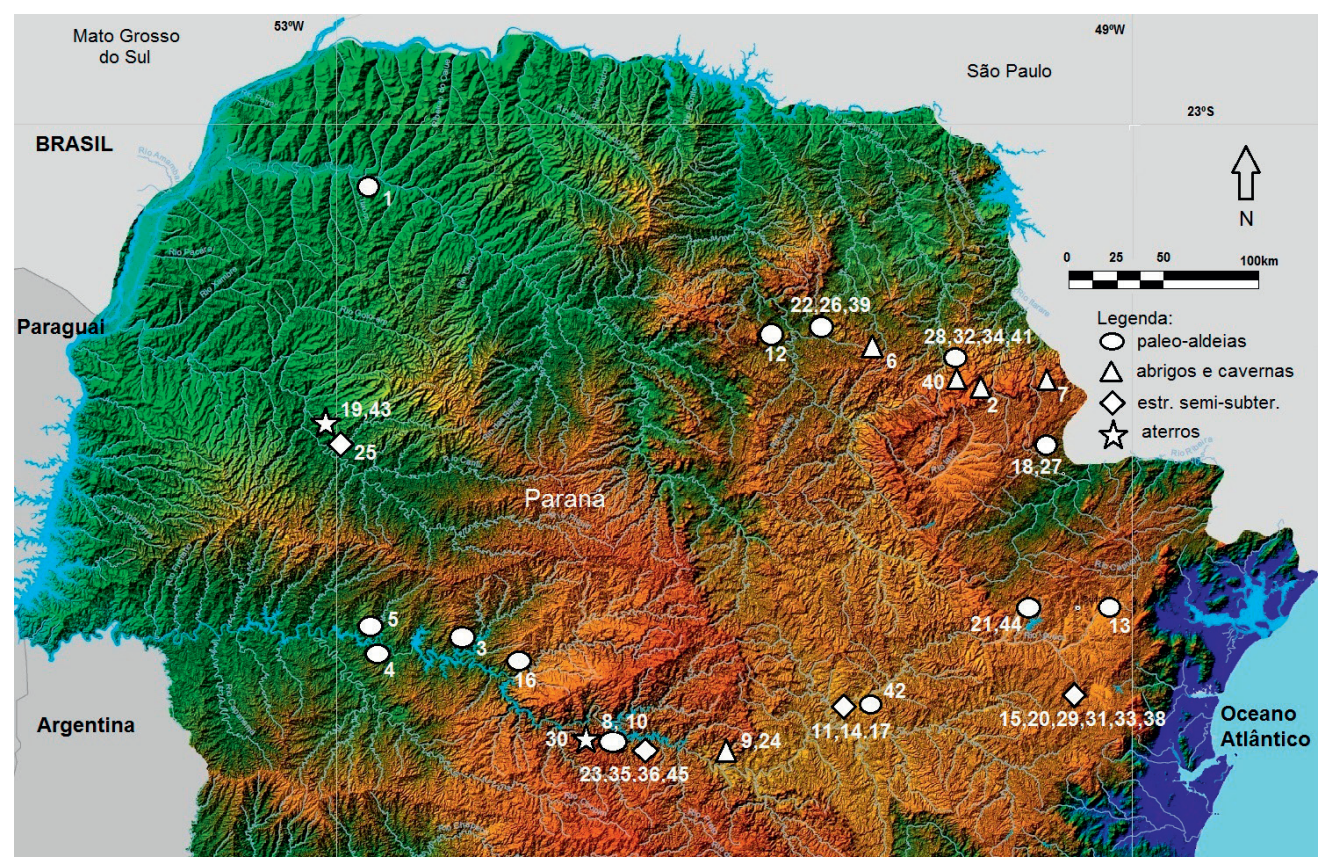

Fig. 1. Mapa com principais sítios Itararé-Taquara datados no estado do Paraná, sul do Brasil, conforme tabelas 1 e 2, sendo a base de relevo adaptado de Morales (2012).

ção Itararé-Taquara, outras com reocupação por outras populações.

A dieta alimentar variável, de acordo com as diferentes especificidades de cada época e subgrupo, nos últimos mil anos baseava-se na coleta de pinhão e mel, na caça e pesca, no cultivo de milho, mandioca, feijão e abóboras, e no manejo ambiental de recursos naturais, alternando o extrativismo com a prática agrícola. O pinheiro araucária, e árvores com frutas importantes na alimentação, como o araçá, a pitanga, e o butiá, tiveram sua área de ocorrência multiplicada através da dispersão planejada de sementes em locais próximos às habitações e roças (Parellada 2005).

Existiam várias estratégias de captura de animais, como os "pari", armadilhas de pesca, descritos no rio Tibagi (Noelli et al. 1996), e muitos paris, além de caminhos, toldos e aldeias, apontados em mapas do Paraná dos séculos XIX e XX.

A cerâmica no Paraná caracteriza-se pelo pequeno volume e espessura fina, com engobo negro ou vermelho, sendo comum a decoração através da impressão de tecido ou malha, carim- bos e incisões em sítios no sul e sudoeste, e as tecnologias de manufatura: o paleteado, a mais antiga, e o acordelado (Parellada 2008). Espículas de espongiários foram identificadas em fragmentos cerâmicos do abrigo Jaguariaíva 1 , município de Jaguariaíva, nordeste do Paraná.

Os líticos representativos são mãos de pilão, lâminas de machado lascadas ou polidas, algumas muito grandes de forma petalóide, com $30 \mathrm{~cm}$ de comprimento, várias com gume reativado lascado, além de lâminas semi-lunares, talhadores, raspadores e lascas. Pontas em virote em rochas básicas, no leste e norte do Paraná, são comuns.

Povos Jê: arte rupestre, abrigos, aterros e aldeias

No Paraná, os Jê assentaram-se especialmente em aldeias a céu aberto, algumas em cristas de morros, como as do alto Ribeira, Serra do Mar e topo de canyons com campos associados a matas de pinheiros Araucária, como em planícies aluviais e litorâneas, e em 
abrigos, algumas vezes com sepultamentos e arte rupestre (Parellada 2005).

Parte das pinturas e gravuras rupestres encontradas no Paraná está relacionada aos Itararé-Taquara (Chmyz 1968b, 1969; Parellada 2003, 2009).

A associação de cultura material arqueológica Jê com painéis rupestres complexos com muitas figuras humanas e a representação de plantas cultivadas, além de possíveis marcas clânicas, evidenciam formas diferenciadas de apropriação da paisagem e de delimitação de territórios. As áreas com vestígios Itararé-Taquara e abrigos com arte rupestre geralmente possuem vários sepultamentos humanos, como o Pontão em Sengés (Parellada 2005), e as evidências de cremação no abrigo Jaguariaíva 1.

Em painel espetacular do abrigo São José da Lagoa 2, no município paranaense de Piraí do Sul, com 0,5x0,7 m, diferenciado de outros no sul do Brasil, aparecem mais de cem figuras humanas, em movimento, envolvidas por três grandes semicírculos (Parellada 2015), parecendo representar um mito Jê (observar figura 2).

Algumas vezes, em locais próximos a sítioshabitação ocorrem pequenos aterros, possiveis sepulturas, como os mapeados nas proximi- dades do sítio Fazenda Marrecas 2, em Dr. Ulysses, Paraná (Parellada 2005). No gasoduto identificaram-se apenas duas estruturas semisubterrâneas, junto ao Abrigo Três Amigos 1, em Cerro Azul, com $3 \mathrm{~m}$ de diâmetro e $1 \mathrm{~m}$ de profundidade. Esse número reduzido talvez se explique pelo duto ter cortado áreas com solos litólicos e encostas íngremes.

No sul de Curitiba, em Fazenda Rio Grande e Mandirituba, Chmyz (1995) e Chmyz et al. (2003) documentaram vários sítios Itararé-Taquara com estruturas semi-subterrâneas, com profundidades entre 0,7 e $2 \mathrm{~m}$, identificadas como habitações.

Sítios com aterros anelares em topos proeminentes, como os de Santa Catarina e Rio Grande do Sul (Saldanha 2005; Iriarte et al. 2013), também foram documentados no município paranaense de Turvo, medindo 80x70x1 $\mathrm{m}$ e vestígios associados, sendo as coordenadas do ponto central UTM SAD 69 22J 7.242.037 $\mathrm{m}$ e $463.162 \mathrm{~m}$, bem como no município de Carambeí, e por Chmyz \& Sauner (1971), no médio Piquiri, com amoladores fixos e conjuntos de "casas subterrâneas", associados a montículos elípticos com altura de 0,4 a 0,5 m,

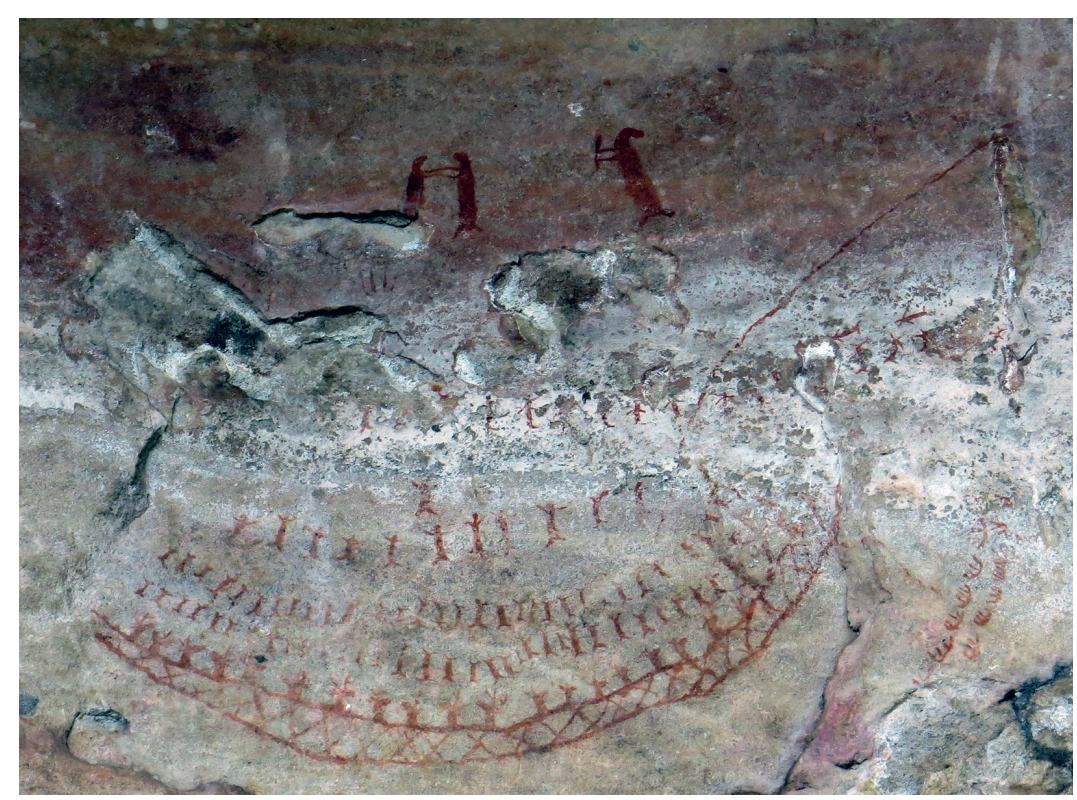

Fig. 2. Pinturas rupestres do abrigo São José da Lagoa 2, Piraí do Sul, Paraná. Foto: Claudia Parellada, 2014. 
e em troncos de cone com valetas circundantes, entre 1,5 e $2 \mathrm{~m}$ de altura.

As estruturas escavadas no solo possuíam diferentes funções, como habitações, locais de sepultamento e áreas de estocagem. As anelares parecem ter comportado danceiros associados a rituais funerários, e também poderiam conter observatórios astronômicos, quando ocorrem associados monolitos e/ou sequências de gra vuras rupestres.

Descrições de aterros e estruturas semi-subterrâneas construídos por indígenas Jê, entre os vales do Piquiri e Iguaçu, aparecem em documentos do século XVII, como as Cartas Ânuas Jesuíticas (Mca I 1951).

O Paraná, pelo Tratado de Tordesilhas em 1494 pertencia à Coroa espanhola, sendo povoado por indígenas Jê e Guarani, que usavam o Peabiru, caminho que ligava a costa atlântica ao Pacífico. Schmidel e nativos Guarani o percorreram, em 1552, partindo de Asunción rumo a São Vicente, e no Ribeira relata-se uma grande aldeia: Scherebethueba (Maack 1968). Staden (2000), em 1557, posiciona Goianá no alto Ribeira, e em 1587, Soares de Sousa (1987) menciona indígenas Guaianá na Serra do Mar.

Muitos dos ramais do Peabiru acabaram originando estradas de colonos na conquista e ocupação do território, bem como os bandeirantes paulistas atacavam o Guairá para capturar índios desde 1585 (Taunay 1924: 23), passando pelos rios Tibagi, Ribeira e Açungui. Nos documentos relativos às comunidades espanholas, entre 1554 e 1632, e às missões jesuíticas, de 1610 a 1631, havia descrições de povos Jê. As missões onde se reuniram indígenas Jê foram: Santo Antonio e San Miguel com Camperos, Cabelludos e/ ou Coronados, e as de Concepción de Nuestra Señora de Guañaños e San Pedro, os Gualachos (Mca I 1951; Parellada 1997).

Nos séculos XVIII e XIX o sul do Brasil era cortado por caminhos de tropas, sendo o mais antigo de Viamão à Sorocaba. No Paraná, especialmente nos Campos Gerais e nos campos de Guarapuava, onde vilas surgiram, eram comuns conflitos entre fazendeiros e populações Jê (Borba 1908; Mota 1998).

\section{Sensoriamento remoto e a disposição espacial dos sítios arqueológicos}

$\mathrm{Na}$ atualidade, o sensoriamento remoto é fundamental para identificar e monitorar mudanças nas paisagens, e caracterizar estruturas arqueológicas, através de anomalias de tons, formas e texturas do relevo, solo, e vegetação (Parellada 2005). A disposição espacial de várias paleo-aldeias pode ser observada, no Paraná, através de fotografias aéreas verticais $P \& B$, vôos 1952 e 1980, escala 1:25.000, e imagens de satélite em cor, como as disponibilizadas pelo Google Earth, de 1999 aos dias atuais. Desde o final do século XX foram destruídas, por subsoladores e máquinas motoniveladoras, muitas estruturas em superfície e no subsolo, frequentes em sítios Itararé-Taquara.

No alto Ribeira delimitaram-se conjuntos de estruturas, aldeias Itararé-Taquara, medindo entre $80 \times 50 \mathrm{~m}$ e $200 \times 200 \mathrm{~m}$, sendo a maioria 100x100 m. As manchas de habitações em Marrecas e Morro Grande, visualizadas nas imagens, mediam de $10 \times 6 \mathrm{~m}$ a $20 \times 8 \mathrm{~m}$, sendo a mais recorrente: $15 \times 6 \mathrm{~m}$. Eram elipses escuras resultado da decomposição e dispersão da matéria orgânica de paredes e da cobertura, com formas originais retangulares e/ou circulares. A direção do eixo maior das habitações era variada, ocorrendo mais, no alto Ribeira e Jaguariaíva, a leste-oeste e a sudoeste-nordeste, e raras vezes, a norte-sul e a sudeste-noroeste.

As paleo-aldeias Itararé-Taquara, visualizadas em Marrecas e Morro Grande, variam entre 1884,96 a 31415,93 $\mathrm{m}^{2}$, sendo circulares a elípticas, existindo poucas lineares associadas a cristas, e em formas de ferradura, adaptadas ao relevo.

\section{Geoarqueologia e variações climáticas}

O estudo da paisagem, na arqueologia, busca uma ampla reconstrução ambiental, sendo fundamentais a descrição topográfica, a disponibilidade de água, o clima, a propensão a secas e inundações, em contexto regional, verificando mudanças ao longo do tempo (Renfrew \& Bahn 1998). Parte das transformações nas paisagens pode decorrer de movimentos de massa, alguns 
originados e/ou ampliados por ocupações em terrenos mais susceptíveis à erosão, como a Serra do Mar.

As paisagens arqueológicas, na visão pós-processualista de Lanata (1997), devem ser estudadas a partir da distribuição espacial do registro, buscando-se a heterogeneidade espaçotemporal, os processos regionais de formação do registro, naturais e culturais, além da ação humana como resposta a variabilidade ambiental.

No nordeste paranaense, em áreas graníticas de relevo íngreme, onde se concentram morros com encostas de alta declividade, e cristas estreitas, existe maior estabilidade nas cristas e menor nas encostas. Intervenções humanas, como a construção de habitações, o traçado de trilhas e caminhos, entre outros, já provocaram, várias vezes, movimentos de massa, como escorregamentos translacionais rasos e rotacionais profundos, que se intensificam com o uso inadequado das vertentes.

Em áreas prospectadas do Gasbol e da LT Bateias-Jaguariaíva os registros de vestígios arqueológicos em rampas, com declividade maior ou igual a $40^{\circ}$, foram poucos. Geralmente os processos de formação de sítios arqueológicos são concomitantes a processos de rastejo, escorregamento e colapso (Parellada 2005).

Em vários perfis e cortes de estradas observados durante as pesquisas no alto Ribeira e Jaguariaíva verifica-se a natureza policíclica dos níveis de erosão, que contribui para formar sítios com aporte de sedimentos, e destruí-los, parcial a totalmente, pelos movimentos de massa. Caracterizaram-se três níveis de pediplanos através das rupturas de declive: terraços de baixa, média e alta vertentes, e os pedimentos ou áreas com sedimentos entre elevações.

Em Marrecas identificaram-se extensas paleo-superfícies, remanescentes de superfícies de pedimentos na faixa de altitudes $740-760 \mathrm{~m}$, onde se encontram solos e paleo-solos alóctones. Os pedimentos, em altitudes mais elevadas constituem formas de relevo mais antigas, e as mais baixas refletem os processos erosivos mais recentes.

Os terraços em encostas mais estáveis do granito Três Córregos, protegidos de inundações e oscilações rápidas da vazão dos cursos de água, comuns em áreas serranas, seriam preferenciais na implantação de sítios líticos e cerâmicos.

A inserção de vários sítios sobre elevações formadas por diques de diabásio é recorrente. Esse fato, observado em sítios Tupiguarani no nordeste paranaense, também aparece no alto Ribeira em sítios Itararé-Taquara. Afinal, solos da decomposição de rochas básicas são mais férteis e propícios ao cultivo agrícola.

No alto Ribeira, em terrenos com calcários, quartzitos, filitos e xistos Açungui, apesar da toponímia ser semelhante a dos granitos, ocorriam poucos sítios. Nos Campos Gerais a distribuição de sítios Itararé-Taquara é irregular em terrenos com afloramentos areníticos, concentrando-se em locais altos e com maior amplitude de observação do entorno.

\section{Conclusões}

Vários sítios Itararé-taquara estão implantados em elementos que se destacam na paisagem: junto a afloramentos de rocha isolados em campos ou florestas, próximos a cachoeiras e/ou bordas de topos de escarpas, em cristas de morros, ou sobre elevações artificiais, como os sambaquis. Mesmo, as estruturas semi-subterrâneas geralmente estão implantadas em topos de planícies e planaltos.

Há 4.000 anos atrás, com a chegada de povos Jê no Paraná ocorreram importantes mudanças culturais, precisava-se aumentar a quantidade de alimento para a subsistência de aldeias com mais indivíduos, e um melhor gerenciamento de recursos com estocagem permitiria esse fato. $\mathrm{O}$ manejo de espécies florestais com frutos, como o pinhão e a pitanga, e o início da prática agrícola, possibilitaram o aumento populacional e a ocupação de novos espaços (Parellada 2005).

A data mais antiga Itararé-Taquara vem do nível intermediário do sítio José Vieira, em Guaporema, datado em 3.435 \pm 175 anos AP (GSY-82), conforme Laming \& Emperaire (1959). Chmyz et al. (1999) relacionam datações radiocarbônicas Itararé-Taquara no centro-sul do Paraná, a fase Açungui entre 3825 a 190 anos AP, a Xagu: de 2355 a 715 anos AP, 
a Candói: 2055 a 715 anos AP, e a Cantu: 845 a 470 anos AP.

Alguns abrigos no nordeste paranaense, com pinturas rupestres em vermelho e preto, com círculos, concêntricos ou raiados, e/ou figuras humanas associadas a cervídeos, apresentam níveis Itararé-Taquara com datações bastante antigas. $\mathrm{O}$ abrigo Jaguariaíva 1 possui $2858 \pm 35$ anos AP (LACUFF 150050), o Caverna Morro Azul 1 - 1941 \pm 35 anos AP (LACUFF 150057), e o da Janela - $1790 \pm 210$ anos AP (ANUA 192-27).

Existe grande quantidade de sítios ItararéTaquara datados entre 1000 e 500 anos AP, dispersos por uma área que abrange do nordeste da Argentina à costa catarinense, inclusive no interior paranaense. Em 950 anos AP aconteceu um grande deslocamento populacional no sentido planalto-litoral, devido às pressões territoriais sofridas pelos Itararé-Taquara em confronto provável com os Tupiguarani (Neves 1988).

Em vários sambaquis da costa do sul do Brasil, principalmente no Paraná e Santa Cata- rina, houve reocupação Itararé-Taquara. Assim, há cerca de 1000 anos atrás pode ter ocorrido um retorno Jê a áreas "míticas" ancestrais, devido a mudanças climáticas, e conflitos com outros grupos, como os Guarani, ao sul, e os Tupi, ao norte.

No alto Ribeira e áreas circunvizinhas, aconteceu uma possivel concentração Jê, entre 1000 e 700 anos atrás, sendo que posteriormente houve nova dispersão e apenas parte desta população permaneceu na região.

A ocupação desse mosaico de paisagens, com relevo montanhoso, com grandes desníveis altimétricos, deve ter sido realizada de modo mais eficaz por certos grupos pré-coloniais, como os Itararé-Taquara, que conheciam empiricamente as rochas, os tipos de solos, os processos erosivos e o manejo florestal.

Novos estudos regionais e um maior número de escavações e datações em sítios arqueológicos, com pouca perturbação, poderão contribuir substancialmente para avanços na compreensão da arqueologia Jê no Paraná.

PARELLADA, C.I.,Transformed landscapes: the archaeology of Jê people in Paraná State, South of Brazil. R. Museu Arq. Etn., 27: 158-167, 2016.

Abstract: In this paper we analyse part of Itararé-Taquara archaeological sites in Paraná, especially paleo-village and rock shelter, in relation to the structure and transformation of the landscape, including geoarchaeological and chronological data, between 4000 and 600 years ago. The spatial arrangement of villages, houses and sacred areas in relation to the relief, the movement of land through the construction of mounds with circular to linear shapes, the digging of semi-underground structures with various functions had been collaborating on reflections on the symbolic aspects of precolonial Jê people in Paraná, Southern Brazil. Furthermore, the arrangement of the monoliths for astronomical observation in order to a better understanding of the cycles of nature improved agricultural production. There was a concentration of Je Indigenous groups in the Upper Ribeira between 1000 and 700 years ago, in coastal plains and high mountains, with large difference in altimetry, demonstrating a traditional knowledge of soils and rocks. Some sites were selected and transformed to mark the control and domination of the territory, thus perpetuating mythical memory.

Keywords: Archaeology of Paraná; Itararé-Taquara potters; Landscape archaeology; Jê archaeology; Rock art. 


\section{Referências bibliográficas}

Araújo, A.G.M. 2001. Teoria e método em arqueologia regional: um estudo de caso no alto Paranapanema, estado de São Paulo. Tese de doutorado. Faculdade de Letras, Filosofia e Ciências Humanas, Universidade de São Paulo, São Paulo.

Araújo, A.G.M. 2007. A tradição cerâmica Itararé-Taquara: características, áreas de ocorrência e algumas hipóteses sobre a expansão dos grupos Jê no sudeste do Brasil. Revista de Arqueologia (SAB), 20: 9-38.

Beber, M.V. 2004. O sistema de assentamento dos grupos ceramistas do planalto sul-brasileiro: o caso da tradição Taquara/Itararé. Tese de Doutorado. UNISINOS, São Leopoldo.

Bauermann, S.G. \& Behling, H. 2009. Dinâmica paleovegetacional da floresta com Araucária a partir do final do Pleistoceno: o que mostra a palinologia. In: Fonseca, C.R. et al. (Ed.). Floresta com Araucária: ecologia, conservação e desenvolvimento sustentável. Ribeirão Preto, Holo, 35-44.

Borba, T.M. 1908. Actualidade indígena. Coritiba, Impressora Paranaense.

Chmyz, I. 1968a. Breves notas sobre petroglifos no segundo planalto paranaense, sítio PR UV 5. Revista do CEPA-UFPR, 1: 53-63.

Chmyz, I. 1968b. Considerações sobre duas novas tradições ceramistas arqueológicas no Estado do Paraná. Pesquisas, Antropologia, 18: 115-125.

Chmyz, I. 1981. Relatório das pesquisas arqueológicas realizadas na área da Usina Hidrelétrica de Salto Santiago (1979-80). Florianópolis/ Curitiba, ELETROSUL/ IPHAN.

Chmyz, I. 1995. Arqueologia de Curitiba. Boletim Casa Romário Martins, 21: 3-54.
Chmyz, I. \& Sauner, Z.C. 1971 Nota prévia sobre as pesquisas arqueológicas no vale do Piquiri. Dédalo, 13: 7-36.

Chmyz, I.; Sganzerla, E.M. \& Volcov, J.E. 1999. Arqueologia da área prioritária do projeto hidroelétrico Tijuco Alto, rio Ribeira, São Paulo, Paraná. Curitiba, CEPA.

Chmyz, I.; Sganzerla, E.M.; Volcov, J.E.; Bora, E.; Ceccon, R.S. 2008. A arqueologia da LT 750kV Ivaiporã-Itaberá III, Paraná-São Paulo. Arqueologia, UFPR, 5: 1-305.

Chmyz, I.; Sganzerla, E.M.; Volcov, J.E.; Bora, E.; Ceccon, R.S. 2009. A arqueologia da Mina Dois Irmãos, em São Mateus do Sul -Paraná. Arqueologia, UFPR, 6: 1-147.

Iriarte, J.; Copé, S.M.; Fradley, M.; Lockhart, J.J.; Gillam, J.C. 2013. Sacred landscapes of the southern Brazilian highlands: understanding southern proto-Jê mound and enclosure complexes. Journal of Anthropological Archaeology, 32 (1): 74-96.

Laming, A. \& Emperaire, J. 1959. A jazida de José Vieira, um sítio Guarani e pré-cerâmico do interior do Paraná. Arqueologia UFPR, 1: $1-148$.

Lanata, J.L. 1997. Los componentes del paisaje arqueológico. Revista de Arqueologia Americana, 13: 151-165.

Langer, J. \& Santos, S.F. 2002. Petróglifos e megálitos no médio rio Iguaçu (PR/SC). Ensino EF Pesquisa, UNESPAR, 1 (1): 74-100.

Maack, R. 1968. Geografia física do Estado do Paraná. Curitiba, Papel. Max Roesner.

Mca I Manuscritos da Coleção De Angelis I. 1951 Jesuitas e Bandeirantes no Guairá (1549. 1640). Introdução por Jaime Cortesão. Rio de Janeiro, Biblioteca Nacional. 
Mota, L.T. 1998. O aço, a cruz e a terra: indios e brancos no Paraná provincial (1853-1889). Tese de doutorado. UNESP, Assis.

Mota, L.T.; Tomasino, K.; Nanni, R.; Noelli, F.S. 2005. Monumentos arqueológicos na Serra do Cadeado, Paraná. [CD-ROM]. Anais do 13 Congresso da Sociedade de Arqueologia Brasileira (SAB). Campo Grande.

Morales, N. (org.). 2012. Projeto neotectônica do Brasil - região Sul. Curitiba, UFPR-UNESP.

Neves, W.A. 1988. Paleogenética dos grupos pré -históricos do litoral sul do Brasil (Paraná e Santa Catarina). Pesquisas (Antropologia), 43: $1-178$.

Nimuendaju, C. 1981. Mapa etno-histórico de Curt Nimuendaju. Rio de Janeiro, IBGE.

Noelli, F.S.; Mota, L.T.; Silva, F.A. 1996. Pari: armadilha de pesca no sul do Brasil e arqueologia. Coleção arqueologia, Porto Alegre, 1 (2): 435-446.

Parellada, C.I. 2003. Pinturas rupestres no centro-leste e nordeste paranaense [CD-ROM]. Anais do XII Congresso da Sociedade de Arqueologia Brasileira (SAB), São Paulo.

Parellada, C.I. 2005 Estudo arqueológico no alto vale do rio Ribeira: área do gasoduto Bolivia -Brasil, trecho X, Paraná. Tese de Doutorado. Museu de Arqueologia e Etnologia, Universidade de São Paulo, São Paulo.

Parellada, C.I. 2007. Arqueologia dos Campos Gerais. In: MELO, M.S. et al. (Org.) Patrimônio natural dos Campos Gerais do Paraná. Ponta Grossa, Editora UEPG, 163-170.

Parellada, C.I. 2008. Tecnologia e estética da cerâmica Itararé-Taquara no Paraná: dados etno-históricos e o acervo do Museu Paranaense. Revista de Arqueologia, 21 (1): 97-111.

Parellada, C.I. 2009. Arte rupestre no Paraná. Revista da FAP, 5: 73-89.
Parellada, C.I. 2015. Arte rupestre no Paraná: novas discussões. Revista Tecnologia e Ambiente, 21 (1): 45-69.

Renfrew, C. \& Bahn, P.G. 1998. Arqueologia: teoria, métodos y prática. Madrid: Akal.

Robrahn, E.M. 1989. A ocupação pré-colonial do vale do rio Ribeira de Iguape, SP: os grupos ceramistas do médio curso. Dissertação de mestrado. Faculdade de Filosofia, Letras e Ciências Humanas, Universidade de São Paulo, São Paulo.

Saldanha, J.D.M. 2005. Paisagem, lugares e cultura material: uma arqueologia espacial nas terras altas do sul do Brasil. Dissertação de mestrado. PUCRS, Porto Alegre.

Schmitz, P.I. 1988 As tradições ceramistas do planalto sul-brasileiro. Documentos, 2: 75-130.

Schmitz, P.I. 1991. Áreas arqueológicas do litoral e do planalto do Brasil. Revista do Museu de Arqueologia e Etnologia, São Paulo, 1: 13-20.

Schmitz, P.I. \& Rogge, J. H. 2008. Um sítio da tradição cerâmica Aratu em Apucarana, PR, Revista do Museu de Arqueologia e Etnologia, São Paulo, 18: 47-68.

Sousa, G.S. 1987. Tratado descritivo do Brasil em 1587. São Paulo, Cia Editora Nacional.

Souza, J.G. \& Merencio, F.T. 2013. A diversidade dos sítios arqueológicos Jê do Sul do Estado do Paraná. Cadernos do LEPAARQ, 10 (20): 93-130.

Staden, H. 2000. Duas viagens ao Brasil. São Paulo, Beca.

Taunay, A.E. 1924. História geral das bandeiras paulistas, t. I, São Paulo, Typografia Ideal.

Urban, G. 1992. A história da cultura brasileira segundo as línguas nativas. In: Carneiro da Cunha, M. História dos indios no Brasil. São Paulo, Cia das Letras, 87-102 